\title{
Bubble curtains attenuate noise from offshore wind farm construction and reduce temporary habitat loss for harbour porpoises
}

\author{
Michael Dähne $e^{1,2, *, * *}$, Jakob Tougaard ${ }^{1, * *}$, Jacob Carstensen $^{1}$, Armin Rose $^{3}$, \\ Jacob Nabe-Nielsen ${ }^{1}$ \\ ${ }^{1}$ Department of Bioscience, Aarhus University, Frederiksborgvej 399, 4000 Roskilde, Denmark \\ ${ }^{2}$ German Oceanographic Museum, Katharinenberg 14-20, 18439 Stralsund, Germany \\ ${ }^{3}$ BioConsult SH GmbH \& Co. KG, Schobüller Str. 36, 25813 Husum, Germany
}

\begin{abstract}
Effects of constructing the DanTysk offshore wind farm (German Bight, 80 turbines, $6 \mathrm{~m}$ diameter foundations) were studied by passive acoustic monitoring of pile-driving noise and harbour porpoise Phocoena phocoena echolocation. An acoustic deterrence device (seal scarer) was used to protect porpoises from hearing loss and bubble curtains were used to attenuate the pile-driving noise. Porpoise occurrence, quantified by echolocation signals, decreased when the seal scarer was engaged, during pile driving and up to $5 \mathrm{~h}$ after pile driving stopped. This effect extended out to $12 \mathrm{~km}$, less than the 18-25 km reported from other pile drivings performed without bubble curtains. The bubble curtains thus effectively reduced the temporary habitat loss and risk of hearing loss. The 2 bubble curtains each attenuated the noise by between 7 and $10 \mathrm{~dB}$, when used separately, and $12 \mathrm{~dB}$ when used together. Attenuation was most pronounced above $1 \mathrm{kHz}$, where the pile-driving noise at larger distances was comparable to or lower than ambient noise. This suggests that noise regulation should be based on frequency-weighted sound levels in addition to broadband levels, to assure that mitigation measures are effective in reducing impact on animals and not only in fulfilling legal requirements. The strong reaction to the seal scarer raises concern that it may surpass the reactions to the pile-driving noise itself, when operating with bubble curtains, and calls for a re-evaluation of the specifications of seal scarer sounds.
\end{abstract}

KEY WORDS: Noise mitigation - Pile driving - Marine construction - Small cetaceans $\cdot$ C-PODs · Phocoena phocoena $\cdot$ Seal scarer $\cdot$ Static acoustic monitoring

\section{INTRODUCTION}

Offshore wind energy has become an important means of meeting the increased demand for renewable energy, and a large number of offshore wind farms have been built during the last $15 \mathrm{yr}$, especially in the southern North Sea. This expansion was initiated by the Danish demonstration project Horns Rev 1 in 2002 (Danish Energy Authority 2006). A key aim of the demonstration project was to address the concern for the possible detrimental impact of offshore wind-farms on marine life. From the start, there

\footnotetext{
*Corresponding author: michael.daehne@meeresmuseum.de

${ }^{* *}$ These authors contributed equally to this work
}

has been particular concern for the harbour porpoise Phocoena phocoena, the most abundant cetacean of Western Europe. The harbour porpoise is under strict protection by the EU Habitats Directive (European Commission 1992), and is commonly considered to be a species particularly sensitive to underwater noise (Southall et al. 2007, Tougaard et al. 2015).

The main concern with respect to marine mammals is underwater noise generated by installation of turbine foundations (Madsen et al. 2006). These foundations, typically steel monopiles or tripod jackets, are installed by percussive pile driving with large

(C) The authors 2017. Open Access under Creative Commons by Attribution Licence. Use, distribution and reproduction are unrestricted. Authors and original publication must be credited. 
hydraulic hammers. This pile driving causes repeated impulsive noise emissions loud enough to cause temporary or permanent hearing loss (temporary or permanent threshold shift, TTS and PTS, respectively) in harbour porpoises at close range (Lucke et al. 2009, Kastelein et al. 2015) and also to affect their behaviour at greater ranges. Thus, several studies of these behavioural reactions to pile-driving noise have shown a large-scale displacement at distances between 18$25 \mathrm{~km}$. Tougaard et al. (2009) found decreased detection rates at least $21 \mathrm{~km}$ at the Horns Rev I wind farm (monopile foundations), and a gradual decrease in responsiveness with distance up to about $18 \mathrm{~km}$ was reported by Brandt et al. (2011) for the construction of Horns Rev II (monopiles). Porpoise detection rates around Horns Rev II based on acoustic loggers were reduced for a period of 24-72 h after the end of pile driving. Dähne et al. (2013a) found that maximum displacement distances (about $25 \mathrm{~km}$ ) observed by passive acoustic monitoring agreed well with aerial counts in the Alpha Ventus wind farm (tripod and jacket foundations), thus supporting the interpretation that porpoises leave the area in response to the noise and that they do not merely change their vocal behaviour. Finally, Haelters et al. (2015) reported displacement distances of approximately $20 \mathrm{~km}$ based on aerial surveys conducted during the construction of the C-Power offshore wind farm (jacket construction) in the Belgian part of the North Sea.

The short- and long-term consequences of the temporary habitat loss caused by the displacement have not been established, but are of considerable interest because of the cumulative nature of the impact. Thus, the population impact of the temporary habitat loss caused by installing a single turbine foundation is likely to be insignificant. Since the impact accumulates over tens or even hundreds of turbines installed in a single wind farm and across several wind farms installed in the same area, the impact on individuals may become large enough to have an effect on the population. Establishing such population effects by direct observation is very difficult, and currently the most promising approach is to study population-level effects of noise on porpoises using population models, such as the individual-based DEPONS model (van Beest et al. 2015) and the PCoD model (King et al. 2015).

Several countries have implemented, or are in the process of implementing, frameworks for regulating noise exposure from pile driving in order to protect marine mammals, including harbour porpoises. The primary target for this regulation has been to prevent hearing damage (TTS or PTS), but often with the sec- ondary effect of reducing displacement of porpoises. So far only Germany (German Federal Ministry for the Environment and Nuclear Safety 2013, Federal Maritime and Hydrographic Agency 2014) and the USA (NMFS 2016) have established legal thresholds for hearing loss, whereas Denmark is in the process (Skjellerup et al. 2015). According to the German legislation, the single-strike sound exposure level (SEL $\mathrm{SS}_{\mathrm{S}}$ as defined by Ainslie 2011) must not exceed $160 \mathrm{~dB}$ re. $1 \mathrm{\mu Pa}^{2} \mathrm{~s}$ and the peak pressure $\left(L_{\mathrm{P}}\right)$ must not exceed $190 \mathrm{~dB}$ re. $1 \mu \mathrm{Pa}$, both at a distance of $750 \mathrm{~m}$ of the pile (German Federal Ministry for the Environment and Nuclear Safety 2013, Federal Maritime and Hydrographic Agency 2014). Appropriate mitigation measures to reduce noise exposure must be taken if levels are predicted to exceed one or both of these thresholds.

Three general methods are available to reduce the impact of noise. The first is a reduction of the noise generated at the source. For offshore wind turbines this can be achieved by selecting other foundation types, such as gravity-based foundations, or alternative installation procedures (Koschinski \& Lüdemann 2014). Modification of the pile-driving procedure itself is another alternative, and systems that prevent generation of the supersonic wave in the pile, which is a main source of noise in the water (Reinhall \& Dahl 2011), are under development. The second method is to reduce the sound energy propagated into the surrounding environment. For offshore wind turbines, such reduction involves an absorbing or shielding barrier around the monopile. The most commonly used barrier is an air bubble curtain, and several studies have confirmed that such bubble curtains can effectively reduce the noise from pile driving (Würsig et al. 2000, Caltrans 2009, Lucke et al. 2011). Further developments have brought the technology to a stage where it can be applied to large pile driving in open waters and in water depths up to about $40 \mathrm{~m}$ (Rustemeier et al. 2012, Diederichs et al. 2014). The third method to reduce impact is to prevent animals from being located in the vicinity of the sound source, thereby reducing the level at the receiver. This means mitigating the amount of noise that animals are exposed to without changing the sound field itself. This can in some cases be obtained very efficiently by time-area restrictions, allowing noisy activities only at times of the day or the year where few or no animals are present in the area. However, if time-area regulation is not feasible (steady or unpredictable presence of animals), animals can instead be deterred to distances where the risk of PTS/TTS is reduced to acceptable levels 
before commencing full-scale pile driving. This deterrence can be achieved using seal scarers, originally developed to keep seals away from aquaculture and fishing gear, but demonstrated to be even more efficient at deterring harbour porpoises (Johnston 2002, Brandt et al. 2012). Also, a gradual increase in hammer impact energy and strike rate (a so-called ramp-up or soft start), as is often done in the beginning of pile driving for pure technical reasons anyway, may also be effective, as it allows porpoises to swim away while being exposed to lower noise levels than during full-energy impact piling. However, the use of a deterrent device and/or soft start will only reduce the risk that porpoises acquire TTS/PTS, but not mitigate the habitat loss associated with the temporary displacement. In fact, a very effective deterrent device may potentially cause a displacement in itself, which is comparable to the displacement caused by the pile driving.

No matter what the objectives are of a regulation of underwater noise exposure, it is critically important that noise levels and regulatory limits are expressed in units that can be linked to the actual effects on the animals (see Southall et al. 2007, Tougaard et al. 2015, NMFS 2016). Such units, applicable to regulation of noise exposure to marine mammals, are hotly debated. The double criterion of the German regulation (one being in units of energy, the other in units of peak pressure), originates in the double criterion devised by Southall et al. (2007). However, the German regulation deviates from Southall et al. (2007) on how to deal with the frequency spectrum of the noise (frequency weighting). The issue of frequency weighting is important, as there is a mismatch between the frequency range of best hearing in porpoises (approximately 10 to $150 \mathrm{kHz}$; Kastelein et al. 2010) and the power spectrum of pile-driving sounds (most energy below $1 \mathrm{kHz}$; Tougaard et al. 2009, Bailey et al. 2010). Southall et al. (2007) proposed the so-called $\mathrm{M}$-weighting $\left(\mathrm{M}_{\mathrm{hf}}\right.$ for high frequency cetaceans such as porpoises), which is a very wide weighting function (see Fig. A1 in the Appendix), based on the limited empirical evidence available at the time. More recently, alternative weighting curves have been based on the shape of the audiogram (e.g. Terhune 2013, Wensveen et al. 2014) and this type of weighting is currently being implemented in US regulation (NMFS 2016). For porpoises there is experimental evidence supporting this type of weighting over Mweighting (Tougaard et al. 2015), both when it comes to predicting levels capable of inflicting TTS and levels causing behavioural deterrence. The German regulation, however, does not specify a frequency weighting and thus only applies to unweighted (broadband) noise levels.

Thus, several important questions remain open in relation to impact of pile-driving noise on marine mammals, in particular, harbour porpoises. The construction of a large offshore wind farm, DanTysk, in the German North Sea gave us the opportunity to measure noise emissions from pile driving of the foundations with and without the use of a bubble curtain at the same time as quantifying the size and temporal extent of the habitat loss sustained by porpoises.

\section{MATERIALS AND METHODS}

Pile-driving noise and porpoise echolocation activity were monitored during construction of the DanTysk offshore wind farm in the German Bight in 2013. The monitoring was carried out with passive acoustic recorders at fixed stations located between 1 and $31 \mathrm{~km}$ from the pile-driving sites.

\section{Study site and construction activities}

The DanTysk wind farm is situated approximately $70 \mathrm{~km}$ from shore in the German Bight on the northern edge of the German Exclusive Economic Zone (EEZ; Fig. 1), bordering the Danish EEZ. The wind farm is located immediately west of the German Natura 2000 area 'Sylt Outer Reef', designated in part based on a high density of harbour porpoises Phocoena phocoena (Gilles et al. 2011). The wind farm extends over approximately $70 \mathrm{~km}^{2}$ of sandy bottom at depths between 21 and $32 \mathrm{~m}$ and consists of 80 turbines (each $3.6 \mathrm{MW}$ nominal capacity, i.e. $288 \mathrm{MW}$ in total). Turbines were mounted on steel monopiles (6 m diameter), which were driven into the seabed with a hydraulic hammer (S-2000 Hydrohammer, IHC Merwede BV). Installation of monopile foundations required on average 4269 strikes (range 2792 to 5634 strikes) and the hydraulic hammer delivered on average $983 \mathrm{~kJ}$ of energy per strike (maximum $1883 \mathrm{~kJ}$ ), i.e. on average $4.1 \mathrm{GJ}$ of cumulated energy (range 3-6.5 GJ) per foundation. The average strike rate was $44 \mathrm{~min}^{-1}$ (range $32-55 \mathrm{~min}^{-1}$ ) and the average time from first to last strike for each foundation was 117 min (range 99-207 min), including short breaks in piling. Pile driving took place in the period from 28 February to 11 December 2013. In this period, 5 breaks longer than $10 \mathrm{~d}$ without pile driving occurred. The most intense period was July-October, 


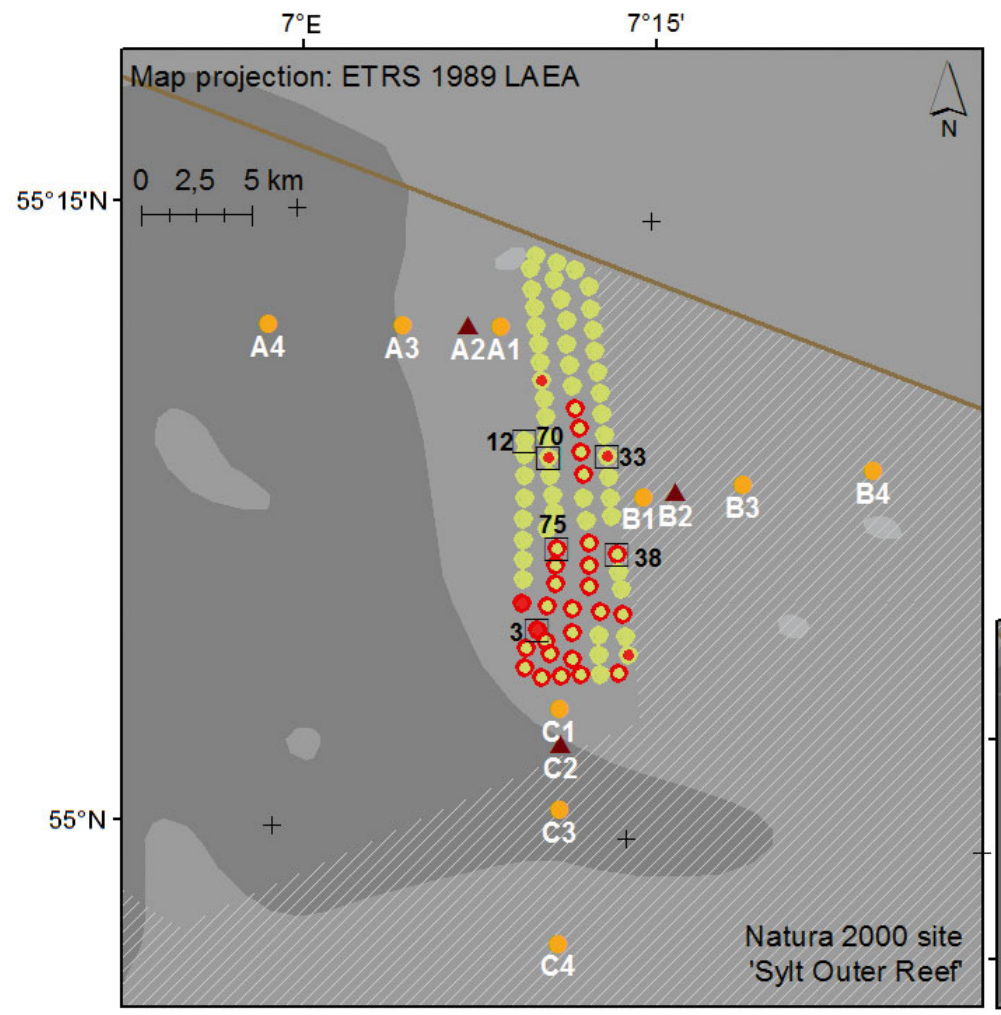

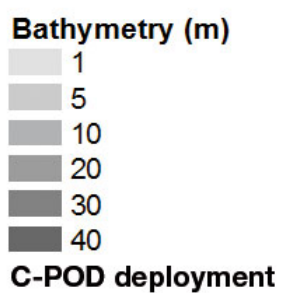

$\Delta$ Without sound recorder - With sound recorder BBC1

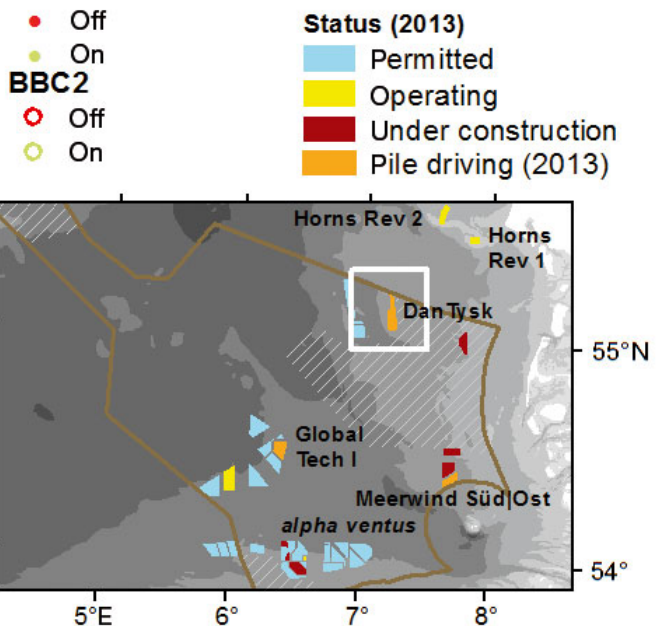

Fig. 1. Left: Foundations for the DanTysk wind farm with locations where C-PODs and sound recorders were deployed and indication of status of bubble curtains used during pile driving (BBC1 and BBC2, see 'Materials and methods: Mitigation measures'). Rectangles highlight foundations from which data have been used in the examples (see Figs. 3 \& 4). Lower right: Overview, indicating offshore wind farms permitted, under construction and in operation close to the DanTysk wind farm during the fieldwork in 2013. During 2013, pile driving was conducted in 2 wind farms other than DanTysk, indicated in orange. Hatched area in both maps indicates the adjacent Natura 2000 area; brown border marks German offshore exclusive economic zone

during which 51 foundations were installed. The median time from the start of installation of one foundation and start of the following installation was $39 \mathrm{~h}$ (range $19-580 \mathrm{~h}$, equal to $0.8-24.2$ days) in this period. Twenty-two of the 80 foundations were installed less than $24 \mathrm{~h}$ after installation of the previous foundation had ended. Four additional foundations for the transformer station (1.8 $\mathrm{m}$ diameter monopiles) were installed between 26 and 29 July 2013 from a separate jack-up rig, and pile driving of these foundations partially overlapped in time with pile driving for 3 turbine foundations.

\section{Mitigation measures}

Deterrence was accomplished by acoustic pingers (Aquamark 100, Aquatec), which emitted broadband signals in the range $20-160 \mathrm{kHz}$ with a source level (SL) of about $145 \mathrm{~dB}$ re. $1 \mu \mathrm{Pa} \mathrm{m}$ (Shapiro et al. 2009), and a seal scarer (Lofitech Seal Scrammer), which emitted $0.5 \mathrm{~s}$ pure tone pulses at about $14 \mathrm{kHz}$ and a nominal SL of about $189 \mathrm{~dB}$ re. $1 \mu \mathrm{Pa}$ m. Pingers and the seal scarer were activated between 37 and $235 \mathrm{~min}$ before each pile-driving session (median $66 \mathrm{~min}$ ). In addition, for technical reasons, each installation began with pile-driving strikes of limited force and variable intervals (soft start).

Two main types of bubble curtains were used alone or in combination to attenuate the radiated noise from pile driving. The first was a large, circular double- or triple-walled bubble curtain (Big Bubble Curtain, Weyres; referred to as BBC1) deployed within a radius of approximately $160 \mathrm{~m}$ from the foundations. The circumference of BBC1 was between 2 and $3 \mathrm{~km}$ and it used on average $0.11 \mathrm{~m}^{3}$ compressed air per meter of tubing per minute, delivered by $4-6$ compressors (total 154 to $231 \mathrm{~m}^{3} \mathrm{~min}^{-1}$ ). A secondary, large bubble curtain (referred to as $\mathrm{BBC} 2$; HydroTechnik) was also used. BBC2 was $500 \mathrm{~m}$ long and fed with either 0.43 or $0.52 \mathrm{~m}^{3}$ compressed air per meter of tubing per minute from either 5 or 6 compressors (total 215 to $260 \mathrm{~m}^{3} \mathrm{~min}^{-1}$ ). It was used either as a circular array, a semi-circular arc or a linear 
array. In the latter 2 configurations, the array was placed so as to reduce the noise radiated into the Natura 2000 area to the east and south of the wind farm. A total of 49 foundations were installed with both $\mathrm{BBC} 1$ and $\mathrm{BBC} 2$ deployed, 19 of which had $\mathrm{BBC} 2$ in a circular layout, 28 as a linear array and 2 cases where the layout of $\mathrm{BBC} 2$ was changed during pile driving on a monopile. Most of the foundations installed with both $\mathrm{BBC} 1$ and $\mathrm{BBC} 2$ deployed were located in the northern part of the wind farm (Fig. 1). Twenty-five foundations were installed with only BBC1, 4 with only BBC2 and 2 foundations entirely without bubble curtains. Additional variations in the use of the bubble curtains included changes to the air-flow rates and the number of active hoses used in BBC1. However, in order to preserve statistical power of the analysis, all foundations were assigned to one of only 4 categories: no bubble curtain, $\mathrm{BBC} 1$ active, $\mathrm{BBC} 2$ active and $\mathrm{BBC} 1+\mathrm{BBC} 2$ active.

\section{Stationary acoustic monitoring}

Twelve monitoring stations were established along 3 transects (A, B and C) to the west, east and south, respectively, each with 4 stations. These positions covered distances from monopiles between 1 and $31 \mathrm{~km}$ (Fig. 1). All stations were equipped with a C-POD (Chelonia) and 9 of the 12 stations were equipped with a sound recorder (DSG-Ocean, Loggerhead). Both C-PODs and sound recorders were anchored about $2 \mathrm{~m}$ above the seabed using a bottom wire suspended between 2 anchor blocks, each marked appropriately by yellow marker buoys.

The C-POD is an autonomous datalogger designed to detect echolocation signals of toothed whales and store summary information about the signals. The CPOD and its predecessor, the T-POD, have proven to be valuable tools in assessing porpoise occurrence in and around offshore wind farms (e.g. Carstensen et al. 2006, Scheidat et al. 2011) and also to quantify displacement of porpoises by pile-driving noise (Tougaard et al. 2009, Brandt et al. 2011, Dähne et al. 2013a). Individual C-PODs were calibrated prior to first deployment (Dähne et al. 2013b). Standard settings provided by the manufacturer were used, and off-line analysis was performed with the KERNO classifier (C-POD.exe version 2.043). The KERNO classifier groups detected clicks into clusters ('trains') and assigns trains to one out of 5 confidence classes, depending on the likelihood that the train originated from a porpoise. Only trains from the 2 best confidence classes were used and from these the number of porpoise clicks per minute was exported for further analysis in SAS (version 9.3) and R (version 3.1.1; R Core Development Team 2014).

Stations close to the pile-driving sites (A1, B1 and C1) were equipped with DSG recorders with lowsensitivity hydrophones to prevent clipping of signals from pilings at close range (HTI96min, High Tech;

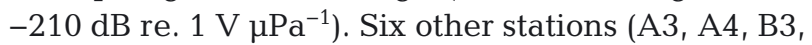
$\mathrm{B} 4, \mathrm{C} 3$ and $\mathrm{C} 4$ ) were equipped with more sensitive

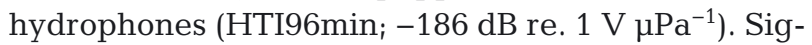
nals were amplified by $10 \mathrm{~dB}$, sampled at $80 \mathrm{ksam}$ ples $\mathrm{s}^{-1}$, digitally low-pass filtered, decimated and stored as 40 ksamples $\mathrm{s}^{-1}, 16$ bit uncompressed files onto SD memory cards, providing $20 \mathrm{kHz}$ of bandwidth in the final recordings. DSG recorders were set to record for 1 min every 3 min.

Monitoring with C-PODs was conducted throughout the entire construction period and resulted in an almost complete dataset, constituting more than $1 \mathrm{yr}$ of data from each of the 12 stations. No instruments were lost, but technical failures resulted in loss of data from a total of 322 station-days in 2013, amounting to $<8 \%$ of the total observation time. Monitoring with DSG loggers lasted only until the end of November and suffered a range of technical problems along the way. This resulted in loss of substantial amounts of data, but due to the highly redundant setup, with 3 loggers in each transect line, there were usable recordings from at least one station for all foundation installations except for the last 4, which took place after the equipment was taken out of the water.

\section{Noise analysis}

Sound files were processed by custom-written routines in MATLAB (MathWorks). For each minutelong recording, the following parameters were extracted: broadband equivalent continuous sound pressure level ( $L_{\text {eq, }}$ equal to RMS average over $1 \mathrm{~min}$ ); sound exposure level cumulated over $1 \mathrm{~min}\left(\mathrm{SEL}_{\mathrm{cum}}\right)_{;}$ and the 50th and 5th percentiles $\left(L_{50}\right.$ and $\left.L_{5}\right)$ for broadband $L_{\text {eq-fast }}$ (running RMS average over nonoverlapping 125 ms windows; Tougaard et al. 2015). Single-strike SEL ( $\mathrm{SEL}_{\mathrm{SS}}$ ) was estimated from $\mathrm{SEL}_{\mathrm{cum}}$ and the average number of strikes per minute $(\bar{n})$ as:

$$
\mathrm{SEL}_{\mathrm{SS}}=\mathrm{SEL}_{\mathrm{cum}}-10 \log _{10}(\bar{n})
$$

Two frequency weightings were applied to all values: an $\mathrm{M}_{\mathrm{hf}}$ weighting sensu Southall et al. (2007) and a custom function fitted to the inverse porpoise audiogram derived from Kastelein et al. (2010), termed $\mathrm{A}_{\mathrm{Ppho}}$. The weighted sound pressure levels, $L_{\mathrm{Mhf}}$ and 
$L_{\mathrm{APpho}}$, were computed from the power density spectrum estimated for each 1-min recording by a Welch average of non-overlapping $1 \mathrm{~s}$ windows (Hannweighted), resulting in an analysis bandwidth $(\Delta f)$ of $1 \mathrm{~Hz}$. The individual $1 \mathrm{~Hz}$ bins were weighted and summed, yielding the weighted sound pressure level:

$$
L_{\text {weighted }}=10 \log _{10} \Sigma\left(\frac{W_{f}}{\max \left(\left|W_{f}\right|\right)}\right)^{2} I_{f} \Delta f
$$

where $I_{f}$ is the power spectrum density $\left(\mu \mathrm{Pa}^{2} \mathrm{~Hz}^{-1}\right)$ at frequency $f$ (in $\mathrm{Hz}$ ), $\Delta f$ is the analysis bandwidth and $W_{f}$ is the weighting curve, given as:

$$
W_{f}=\frac{f_{\text {high }}^{2} f^{2}}{\left(f_{\text {high }}^{2}+f^{2}\right)\left(f_{\text {low }}^{2}+f^{2}\right)}
$$

where $f_{\text {low }}$ and $f_{\text {high }}$ are constants specific to either the $\mathrm{M}$-weighting curve or the inverted audiogram curve. For the $\mathrm{M}_{\text {hf }}$ curve, $f_{\text {low }}$ and $f_{\text {high }}$ are $200 \mathrm{~Hz}$ and $180 \mathrm{kHz}$, respectively (Southall et al. 2007). For the inverted audiogram, the values were determined empirically to obtain best fit to the porpoise audiogram: 10 and $300 \mathrm{kHz}$, respectively. This weighting function is for all practical purposes identical to the inverted audiogram weighting function for high frequency cetaceans given by the NMFS (2016). Weighting functions can be found in Appendix Fig. A1.

\section{Statistical analysis}

To quantify the effects of pile driving and the seal scarer, the C-POD time series was partitioned into 4 periods. The first period (termed 'before') was the last $3 \mathrm{~h}$ before the seal scarer was turned on. This period was not quiet, as there were other noises associated with moving the hydraulic hammer and monopile into place and other activities related to the general construction activities, but nevertheless serves as the reference to the impact of the seal scarer and the pile driving. The second period, termed 'deterrence', was the variable period where the seal scarer was active before pile driving began. The third period was the pile driving, which was of variable duration, and the fourth period (termed 'after') was the $24 \mathrm{~h}$ after cessation of pile driving. The fourth period was further subdivided into consecutive $1 \mathrm{~h}$ periods, giving a total of 27 periods in the analysis: 1 'before' (3 h), 2 impact ('deterrence', between 0.5 and $4 \mathrm{~h}$, and 'piling', between 2 and $4 \mathrm{~h}$ ) and up to twenty-four $1 \mathrm{~h}$ 'after' periods. If deterrence for the installation of the next foundation started earlier than $24 \mathrm{~h}$ after cessation of piling, the overlapping periods were not included as 'after' periods.
The percentage of porpoise positive minutes (\%PPM) was calculated for each of the 80 foundations and each of the up to 27 periods. \%PPM was computed as the ratio of minutes with porpoise click detections to total number of minutes in each period and was assumed to be described by an overdispersed binomial distribution. The data were thus analysed using a generalized linear mixed-effects model with foundation number as a random factor for pairing observations belonging to piling at the same foundation, and an over-dispersion factor to account for larger variation in \%PPM than prescribed by the binomial distribution. Furthermore, a first-order autocorrelation for the residuals within each pile driving was included as a repeated measures effect. Differences between periods were calculated as contrasts between parameter estimates from the model. The analysis was stratified by distance to the foundation by aggregating data into distance groups: $1.5-3 \mathrm{~km}$, 3-6 km, and so forth up to $15-18 \mathrm{~km}$ from the monopile.

Bubble curtains were either on or off throughout the entire time it took to complete one installation of a monopile, meaning that the efficacy of the bubble curtains could not be determined directly by comparing recordings with and without bubble curtains within the same installation. Instead, the efficacy of the bubble curtains was estimated by a generalized additive model (GAM) with a Gaussian error distribution and an identity link function (Wood 2011) of the $L_{\text {eq }}$ from each recorded minute as the dependent variable. Distance from monopile was modelled as a thin plate smoother with 4 degrees of freedom and the mode of the bubble curtains (none, $\mathrm{BBC} 1, \mathrm{BBC} 2$ and $\mathrm{BBC} 1+\mathrm{BBC} 2)$ as a factorial interaction term to determine whether the effect of the bubble curtains was additive or whether the attenuation of both bubble curtains was larger or smaller than the sum of their individual attenuations.

\section{RESULTS}

\section{Effect of pile driving on porpoise detections}

Pile-driving operations had a pronounced effect on echolocation activity of harbour porpoises Phocoena phocoena as recorded by C-PODs (Table 1). Baseline levels of echolocation activity, expressed as $\% \mathrm{PPM}$, were between $4 \%$ and $6 \%$ (green circles in Fig. 2). During pile-driving, \%PPM was significantly lower than baseline up to $12 \mathrm{~km}$ from the pile-driving site (between $1 \%$ and $3 \%$; Fig. 2, red circles, 
Table 1. Coefficient estimates (est) and p-values for testing differences between mean percent porpoise positive minutes (\%PPM) in the $3 \mathrm{~h}$ before start of seal scarer/pingers (baseline) versus the following periods with seal scarer/pingers, pile driving and the first $10 \mathrm{~h}$ of recovery. For each comparison and distance class the p-value is indicated. Significant tests $(\mathrm{p}<0.05)$ are in bold. Trends $(\mathrm{p}<0.1)$ are in italic. All significant tests indicated a decrease in mean \% PPM compared to baseline

\begin{tabular}{|c|c|c|c|c|c|c|c|c|c|c|c|c|}
\hline \multirow[t]{2}{*}{ Before versus } & \multicolumn{2}{|c|}{$1.5-3 \mathrm{~km}$} & \multicolumn{2}{|c|}{$3-6 \mathrm{~km}$} & \multicolumn{2}{|c|}{$6-9 \mathrm{~km}$} & \multicolumn{2}{|c|}{$9-12 \mathrm{~km}$} & \multicolumn{2}{|c|}{$12-15 \mathrm{~km}$} & \multicolumn{2}{|c|}{$15-18 \mathrm{~km}$} \\
\hline & est & $\mathrm{p}$ & est & $\mathrm{p}$ & est & $\mathrm{p}$ & est & $\mathrm{p}$ & est & $\mathrm{p}$ & est & $\mathrm{p}$ \\
\hline Seal scarer/pingers & 1.42 & 0.001 & 0.47 & 0.002 & 0.59 & 0.000 & 0.38 & 0.000 & 0.24 & 0.087 & 0.52 & 0.001 \\
\hline Pile driving & 1.25 & 0.004 & 0.47 & 0.003 & 0.82 & 0.000 & 0.62 & 0.000 & 0.03 & 0.829 & 0.17 & 0.196 \\
\hline $0-1 \mathrm{~h}$ recovery & 0.43 & 0.472 & 0.44 & 0.036 & 0.52 & 0.001 & 0.51 & 0.002 & -0.13 & 0.454 & 0.00 & 0.982 \\
\hline $1-2 \mathrm{~h}$ recovery & 0.49 & 0.416 & 0.37 & 0.076 & 0.47 & 0.003 & 0.53 & 0.001 & 0.24 & 0.195 & -0.06 & 0.703 \\
\hline $2-3$ h recovery & 0.74 & 0.266 & 0.34 & 0.097 & 0.51 & 0.001 & 0.53 & 0.002 & 0.35 & 0.075 & 0.01 & 0.971 \\
\hline $3-4 \mathrm{~h}$ recovery & 0.04 & 0.932 & 0.11 & 0.572 & 0.51 & 0.001 & 0.35 & 0.026 & 0.25 & 0.188 & -0.23 & 0.159 \\
\hline $4-5 \mathrm{~h}$ recovery & -0.10 & 0.838 & -0.06 & 0.754 & 0.35 & 0.019 & 0.43 & 0.008 & 0.26 & 0.160 & 0.01 & 0.955 \\
\hline $5-6$ h recovery & -0.08 & 0.866 & -0.11 & 0.567 & 0.22 & 0.136 & -0.07 & 0.600 & 0.41 & 0.037 & 0.16 & 0.397 \\
\hline $6-7$ h recovery & -0.02 & 0.957 & 0.13 & 0.497 & 0.06 & 0.679 & 0.02 & 0.916 & 0.27 & 0.155 & 0.14 & 0.440 \\
\hline $7-8 \mathrm{~h}$ recovery & 0.74 & 0.182 & 0.09 & 0.661 & 0.09 & 0.525 & -0.06 & 0.661 & 0.06 & 0.727 & 0.01 & 0.948 \\
\hline 8-9 h recovery & -0.87 & 0.024 & 0.13 & 0.517 & -0.08 & 0.580 & 0.16 & 0.277 & 0.06 & 0.728 & 0.09 & 0.614 \\
\hline 9-10 h recovery & -0.37 & 0.378 & -0.18 & 0.337 & 0.08 & 0.560 & 0.22 & 0.142 & 0.07 & 0.702 & 0.04 & 0.816 \\
\hline
\end{tabular}

and Table 1), and for the intermediate ranges (6$12 \mathrm{~km}) \%$ PPM remained significantly lower than baseline for $5 \mathrm{~h}$ after pile driving ended (Table 1). At closer ranges $(<6 \mathrm{~km}) \%$ PPM remained low for a period between 3 and $5 \mathrm{~h}$ after the end of pile driving, but this was not statistically different from baseline levels (Table 1). However, the sample size in this range interval was relatively low (reflected by the larger error bars in Fig. 2), as only few foundations were located within $6 \mathrm{~km}$ of a recording station, thus providing less statistical power in this range. In the range $12-15 \mathrm{~km}$, a single interval (5-6 h after end of pile driving) was significantly different from baseline (Fig. 2E, Table 1), but this is likely a spurious effect ( $p=0.0343$ ). From $6 \mathrm{~h}$ after cessation of pile driving and onwards, the \%PPM fluctuated considerably, but was not statistically different from baseline levels (Table 1). Such spurious significances were also found $8-9 \mathrm{~h}$ after pile driving in the 1.5 to $3 \mathrm{~km}$ range and $5-6 \mathrm{~h}$ after pile driving in the $12-15 \mathrm{~km}$ range.

\section{Effect of the seal scarer}

Porpoise echolocation activity was affected not only by pile driving, but also by acoustic deterrence (pingers and seal scarer; Fig. 2, yellow circles). Thus, $\%$ PPM dropped significantly relative to baseline levels for all ranges, except for the $12-15 \mathrm{~km}$ range interval, where the decrease was not statistically significant (Table 1). The largest decrease was seen at close range, $1.5-3 \mathrm{~km}$ from the foundations, where $\%$ PPM fell to about $0.5 \%$.

\section{Pile-driving noise}

Examples of broadband noise levels recorded during complete pile-driving operations at 3 different locations are shown in Fig. 3. During pile driving, the noise level measured as broadband equivalent sound pressure level $L_{\text {eq }}$ over $1 \mathrm{~min}$ intervals increased at least $20 \mathrm{~dB}$ above ambient/system noise on all recording stations. The gradual build-up of noise levels during the soft start was also evident. In some of the recordings, noise from pile driving in wind farms other than DanTysk was detectable above ambient/ system noise, and noise from pile driving made during installation of the transformer station at DanTysk was clearly detectable (an example shown is in Fig. 3C).

There was considerable variation in the duration of pile driving and the number and duration of breaks in the pile-driving sequence among the foundations. This variability, caused by variability in seabed conditions among foundations and different technical obstacles encountered, is inherent to the dataset and will have added to overall variability in the aggregated noise data.

\section{Effect of bubble curtains}

The 2 bubble curtains effectively reduced the noise radiated from foundations during pile driving, individually and in combination. This is most clearly seen in the examples shown in Fig. 4, where signals recorded with bubble curtains active (in particular $\mathrm{BBC} 2$ and $\mathrm{BBC} 1+\mathrm{BBC} 2$ ) have peak-to-peak levels up 

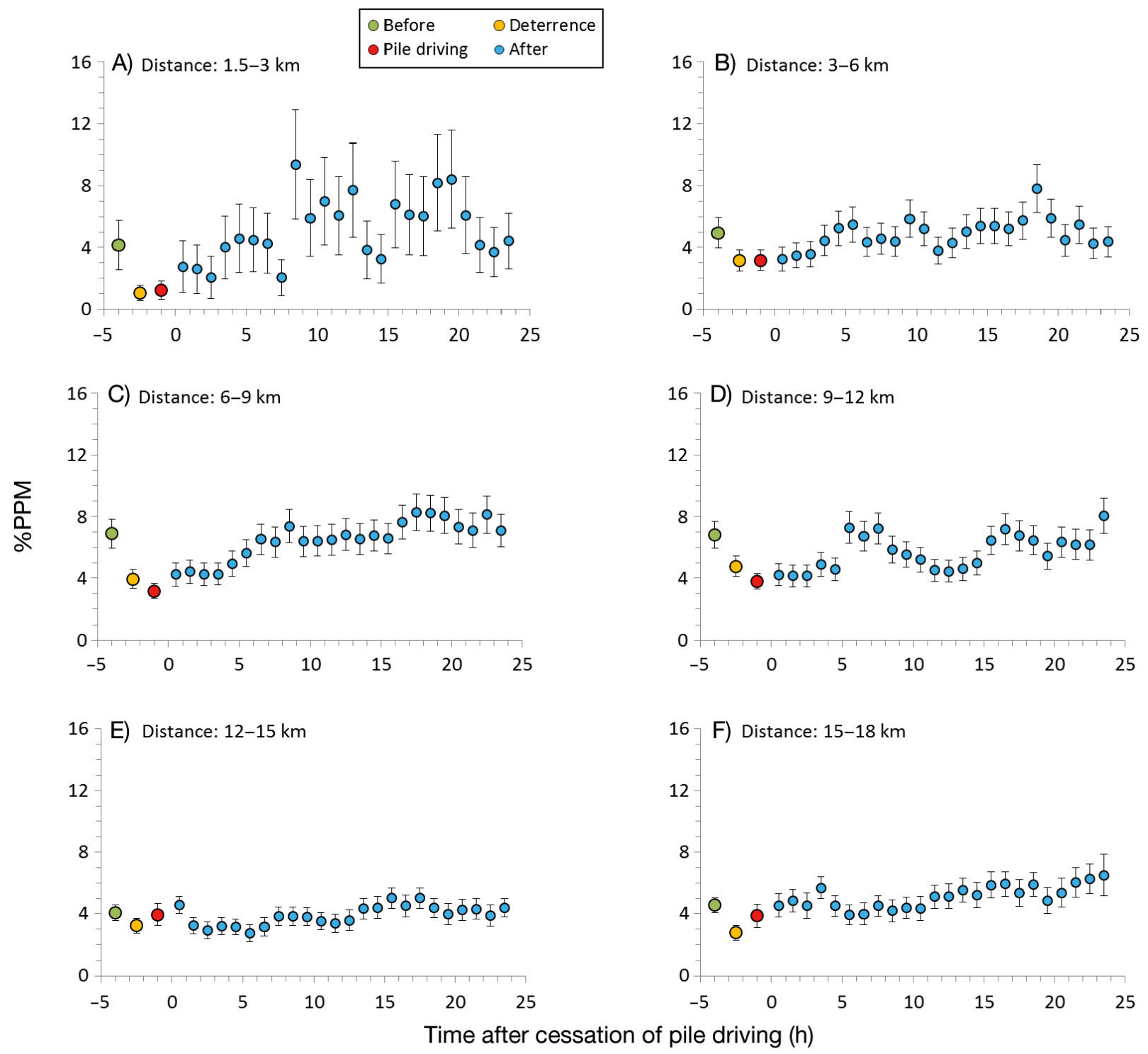

Fig. 2. Percentage porpoise positive minutes (\%PPM) for periods associated with pile-driving operations. Statistics comparing period-specific means are found in Table 1. Green: $3 \mathrm{~h}$ period before seal scarer/pingers were switched on; orange: period with seal scarer/pingers on; red: pile-driving period; blue: successive $1 \mathrm{~h}$ periods after pile driving stopped. Error bars show SEM. The analysis was stratified into 6 classes, according to distance from the pile-driving site; each class is illustrated by one subfigure

to $24 \mathrm{~dB}$ lower than the unmitigated signals. The effect is also apparent in Fig. 5, when expressed both as SEL (left panels) and as the 5th percentile of $L_{\text {eq-fast, }}$ and is seen as a clustering of larger symbols (no bubble curtains) in the upper part of the figure, whereas the smaller symbols (both bubble curtains) cluster in the lower part of the figure. The effect of the bubble curtains was evident for all 3 frequency weightings (broadband, M-weighted and inverse audiogram weighted).

The effectiveness of the bubble curtains is even more striking when evaluating the frequency spectra of the signals (Fig. 4, right panel, and Fig. 6). Bubble curtains were particularly effective at attenuating noise above $1 \mathrm{kHz}$. Without bubble curtains, considerable energy was recorded up to about $5 \mathrm{kHz}$ even $15 \mathrm{~km}$ from the piling site (Fig. 4, bottom right, red curve), whereas levels recorded with one or more bubble curtains active are 10-30 dB lower (Fig. 4, bottom right, green, blue and magenta lines). At close range $(<6 \mathrm{~km})$, where less-sensitive hydrophones were used, the reduction in noise above a few $\mathrm{kHz}$ was down to the level of the electronic noise floor of the hydrophones $\left(\sim 65 \mathrm{~dB}\right.$ re. $\left.1 \mu \mathrm{Pa}^{2} \mathrm{~Hz}^{-1}\right)$; at further 

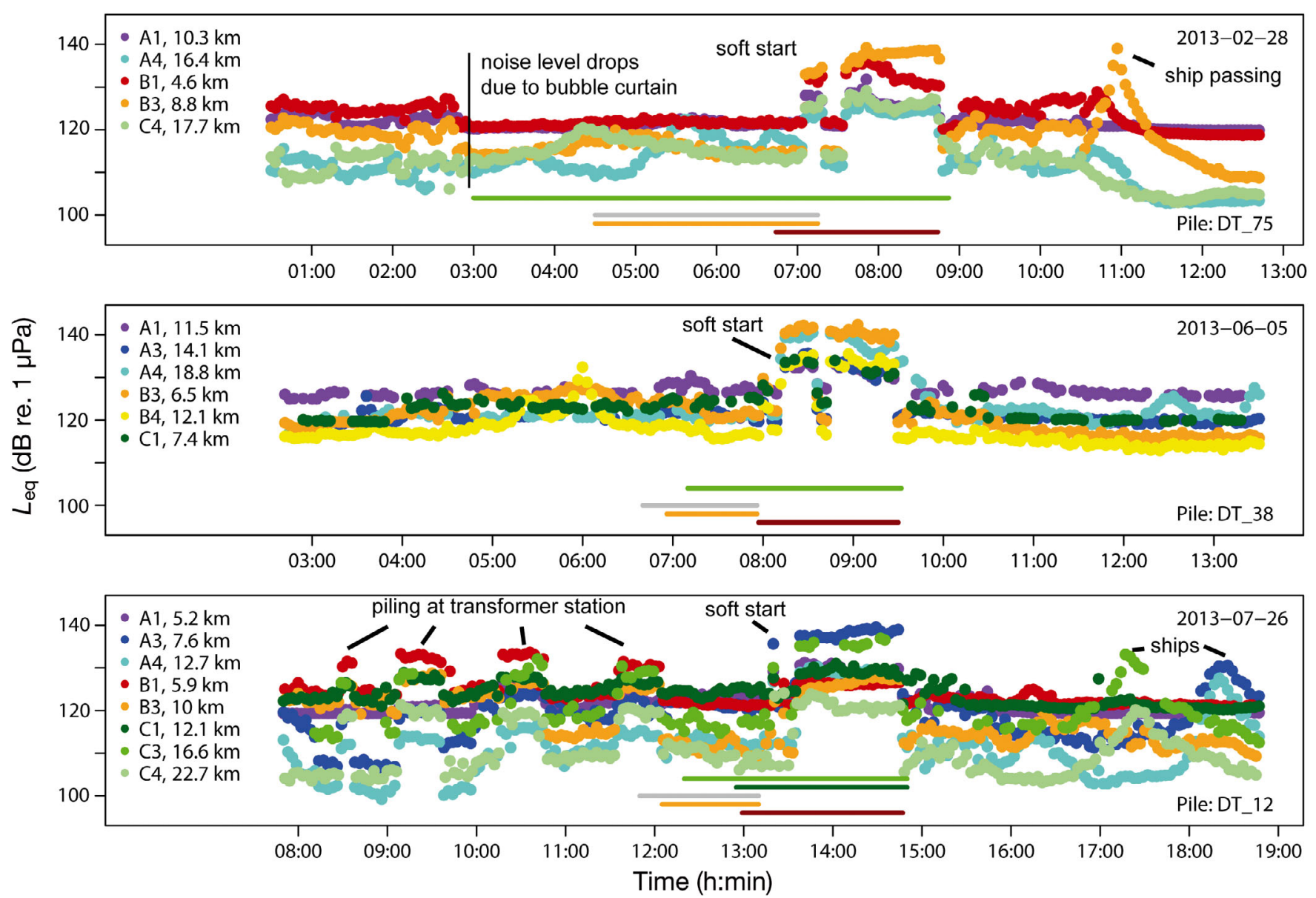

Fig. 3. Equivalent sound pressure levels $\left(L_{\text {eq }}\right)$ measured over 1 min intervals every third minute through 3 complete foundation installations. The distance to the pile-driving site is indicated for each recording station. Horizontal lines indicate different activities: green: bubble curtain 1 (BBC1) active; dark green: bubble curtain 2 (BBC2) active; grey: pingers active; orange: seal scarer active; red: pile driving on foundation. In top panel, a decrease in ambient noise occurs at the closest station (B1) at around $02: 50 \mathrm{~h}$, coinciding with the time when the first bubble curtain is turned on (indicated by a line), suggesting that the bubble curtain attenuates a noise source located inside the bubble curtain, possibly from the jack-up rig itself. Four instances of increased noise levels before pile driving started at DanTysk in the bottom trace are due to pile driving at the nearby transformer station. The gradual rise, peak and decline of the noise level at Stn B3 in the top trace around 17:00 h and at 17:15 and 18:30 h on Stns A3 and C3 are due to ships passing close to the recording stations

distances $(>6 \mathrm{~km})$, recorded at stations with a higher hydrophone sensitivity, the reduction was down to the level of the ambient noise (Fig. 6). However, there was substantial variation in received levels across different pile drivings, even when distance was taken into account and the effect of the bubble curtain was separated (Figs. 5 \& 7). The 2 foundations installed without bubble curtains resulted in the highest measured noise levels. There was a large variation, up to $30 \mathrm{~dB}$, in the measured levels recorded from different foundations, but at the same distances (seen as the vertical dispersion of points in Fig. 7).

Attenuation of the bubble curtains is illustrated in Fig. 7 and was found to be comparable for the 2 bubble curtain systems used (Table 2). The bubble cur- tains attenuated the received broadband $L_{\text {eq }}$ by on average $8.7 \mathrm{~dB}$ for $\mathrm{BBC} 1$ and $8.1 \mathrm{~dB}$ for $\mathrm{BBC} 2$ over the entire range of distances from 1.5 to $30 \mathrm{~km}$ from the pile driving. When the two bubble curtains were used together, their combined average attenuation was $12.5 \mathrm{~dB}$. Hence, the total attenuation of the 2 bubble curtains acting together was less than the sum of the individual attenuation of each bubble curtain, their combined attenuation being on average $4.3 \mathrm{~dB}$ less than expected from the sum of the individual attenuations. The model resulted in essentially similar results when run on M-weighted levels (data not shown), but audiogram-weighted levels had higher than expected attenuation between 10 and $20 \mathrm{~km}$, and less than expected attenuation above 

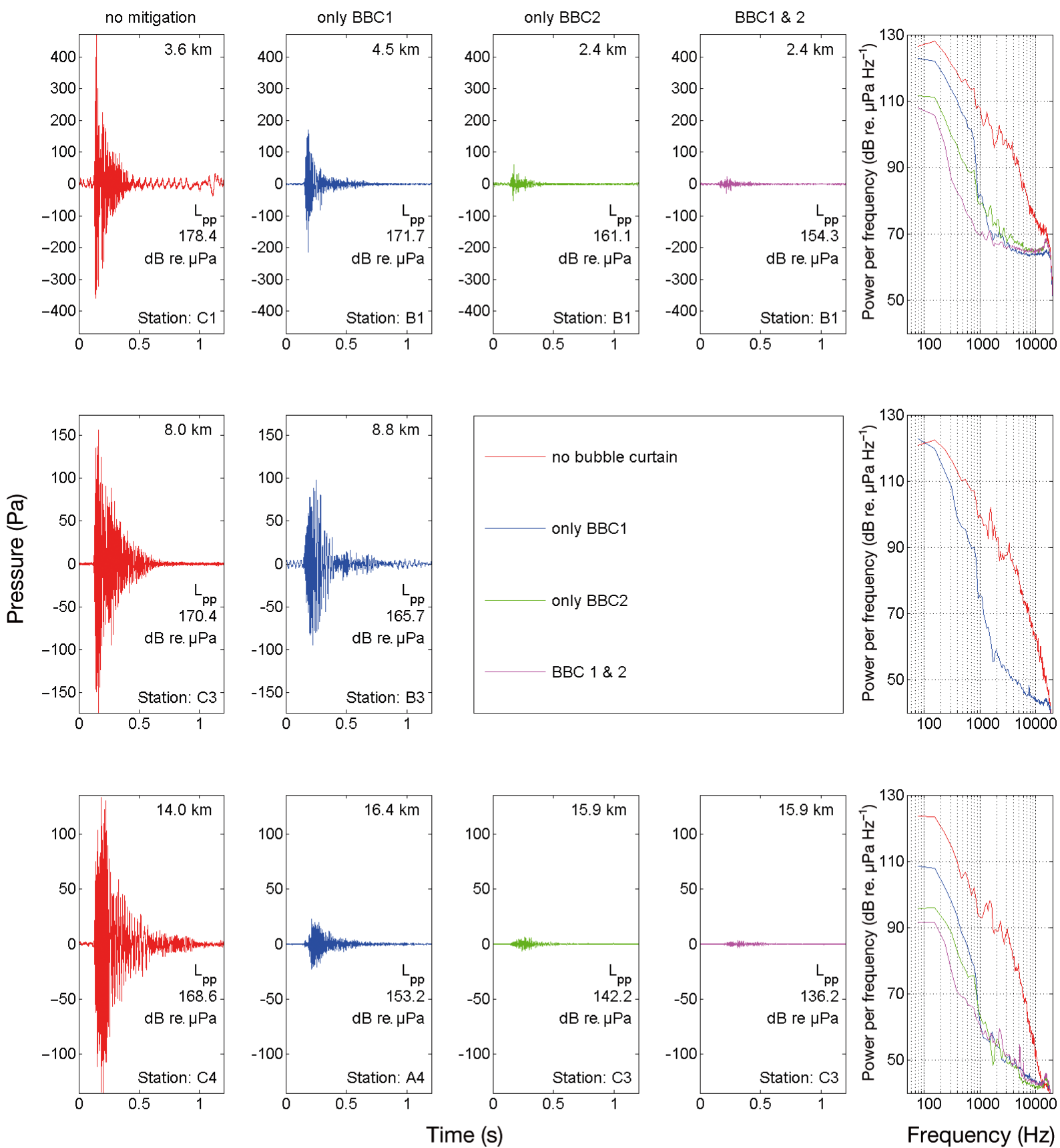

Fig. 4. Examples of pile-driving sounds recorded at different distances (downwards: same foundation, but not exactly the same pulse) and with different combinations of bubble curtains (across: different foundations). Example without bubble curtain from foundation 3; $\mathrm{BBC} 1$ alone from foundation 75; and $\mathrm{BBC} 2$ alone and $\mathrm{BBC} 1+\mathrm{BBC} 2$ from foundation 33 (see Fig. 1 for their locations relative to recording stations). No matching recordings were available for $\mathrm{BBC} 2$ alone or $\mathrm{BBC} 1+\mathrm{BBC} 2$ at intermediate ranges. $\mathrm{L}_{\mathrm{pp}}$ : peak to peak sound pressure level of the pulse. Rightmost panels show power spectral densities (Welch average, Hann window, 512 samples, $75 \%$ overlap) of the pulses

$20 \mathrm{~km}$. These deviations are likely due to a combination of the high self-noise of the hydrophones used close to the pile-driving site, and the relatively stable noise levels recorded beyond $10 \mathrm{~km}$ dominated by the ambient noise. Audiogram-weighted data were thus excluded from further analysis.

\section{DISCUSSION}

Installation of pile driving at the DanTysk offshore wind farm caused displacement of harbour porpoises Phocoena phocoena during and immediately after pile-driving operations. However, the maximum re- 


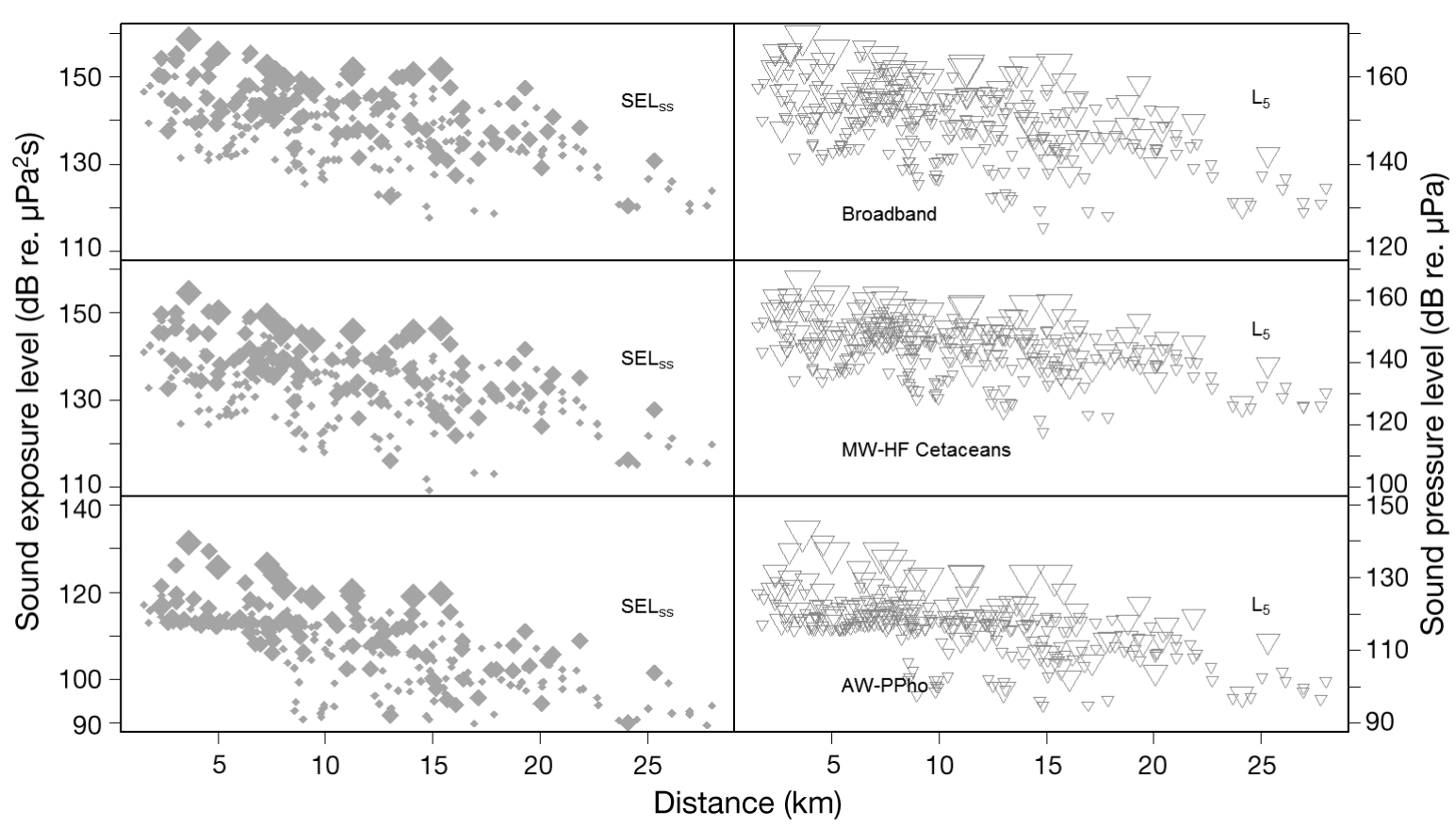

Fig. 5. Sound levels registered during pile driving at the wind farm site. Each data point represents one individual pile-driving event. Filled diamonds: SEL ${ }_{S S}$, single strike sound exposure level (SEL), computed from SEL $_{\text {cum }}$ with Eq. (1); triangles: $L_{5}$, upper 5th percentile of $L_{\text {eq-fast }}$. Large markers show pilings with no bubble curtain in operation, medium-sized markers show one bubble curtain in operation and small markers show both bubble curtains in operation

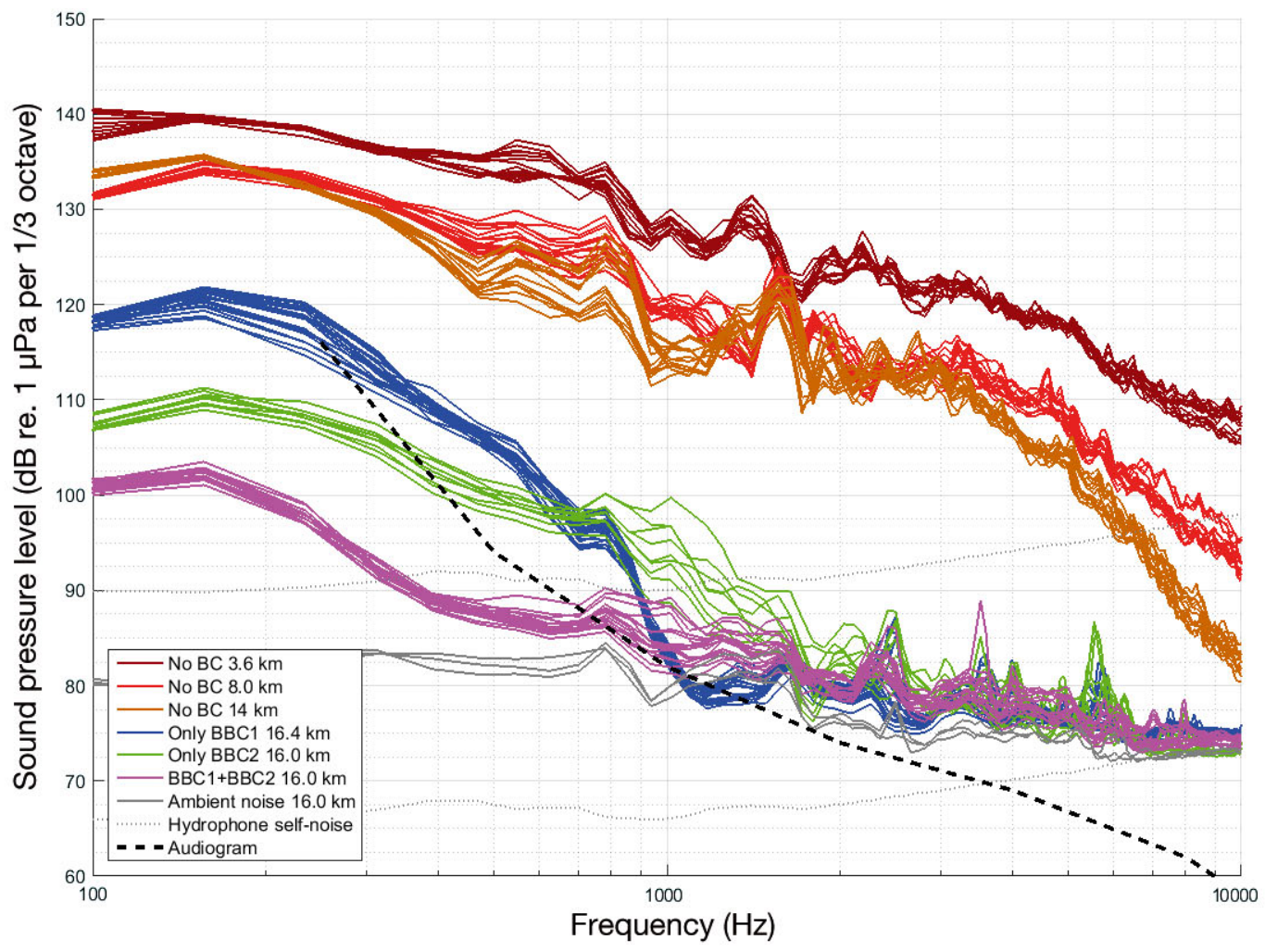

Fig. 6. Representative spectra of pile driving noise, without bubble curtains (no BC; red), BBC1 (blue), BBC2 (green) and $\mathrm{BBC} 1+\mathrm{BBC} 2$ (magenta). In grey are examples of ambient noise spectra, recorded a few hours prior to one of the pile drivings. Dotted grey lines indicate electronic noise floor of the recording systems (low gain and high gain). Each curve represents the Welch-averaged power density spectrum of a 1-min recording with continuous pile driving, converted to 1/3-octave levels (by adding $10 \log [0.23 f]$ to each point of the curve) to allow a direct comparison with the harbour porpoise audiogram (Kastelein et al. 2010), under the standard assumption that porpoise hearing can be modelled as a filter bank with 1/3 octave filters 


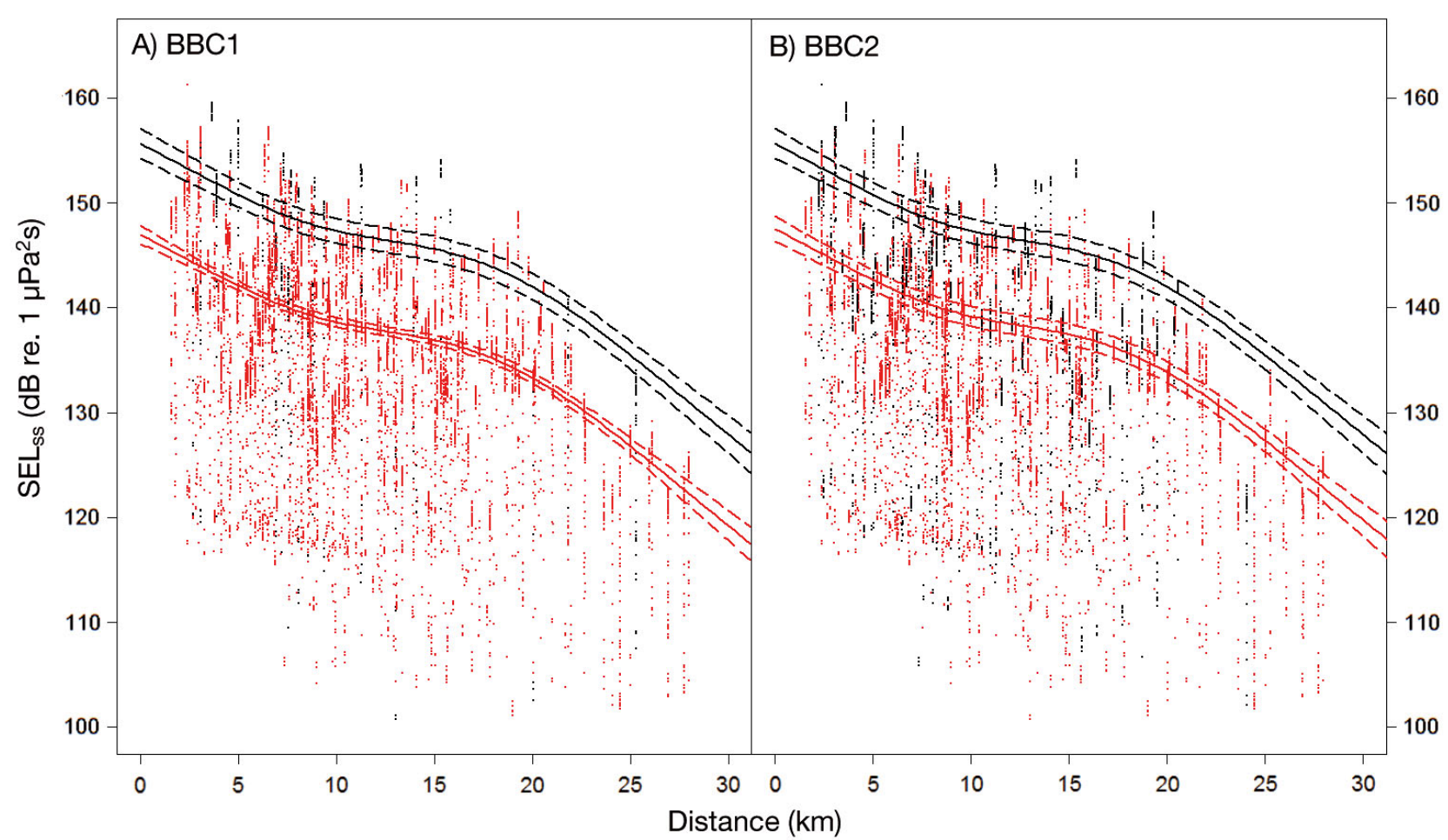

Fig. 7. Effect of bubble curtains on underwater noise from pile driving. Each point represents the mean single-strike sound exposure level (SELSS) of a 1-min recording. Black indicates pilings without bubble curtains and red colour indicate pilings using at least one bubble curtain. Whereas BBC1 was often used as the only bubble curtain, BBC2 was mostly used together with $\mathrm{BBC} 1$. Data points are clustered along vertical lines due to the numerous replicate 1-min intervals at the same distance during each pile driving

action range was found to be $12 \mathrm{~km}$ from the construction site, considerably less than what has been observed at other wind farms. Displacement distances for wind farms constructed with similar sized monopiles but without bubble curtains ranged between 18 and $25 \mathrm{~km}$ (Tougaard et al. 2009, Brandt et al. 2011, Haelters et al. 2015). Thus, the reaction distance at DanTysk was about half of what has been reported for unmitigated pile drivings, which translates into a $75 \%$ reduction in the exposed area and therefore also in the number of affected animals. This compares well to findings from the Borkum West II wind farm, where bubble curtains led to a $90 \%$ decrease in the affected area from 15 to $5 \mathrm{~km}$ (Nehls et al. 2016). Furthermore, the displacement at DanTysk lasted on average up to $5 \mathrm{~h}$ after the end of pile driving, which is less than the 24 to $72 \mathrm{~h}$ observed during the construction of Horns Rev II (Brandt et al. 2011; no bubble curtain). The study at Horns Rev I (Tougaard et al. 2009; without bubble curtains) did not quantify return time directly, but measured instead time from the end of pile driving until the return of the first porpoise. This was about $6 \mathrm{~h}$, but the time until porpoise densities reached baseline levels is likely to have been higher than this, as porpoises are expected to return gradually.
Even though no direct comparison was possible within the DanTysk pile drivings, it must be stated that reaction distances and delay of return after the

Table 2. Summaries of the models presented in Fig. 7. Intercept of the model represents the mean value of equivalent sound pressure level $\left(L_{\mathrm{eq}}\right)$ across all distances. Estimates for $\mathrm{BBC} 1 / \mathrm{BBC} 2$ on/off represents the mean attenuation of the bubble curtain for the specific setting. The 'Both active' covariate is additive, so when both bubble curtains are working, the effect is $-8.7-8.1+4.3=-12.5 \mathrm{~dB}$

\begin{tabular}{|c|c|c|}
\hline \multirow[t]{2}{*}{ Factorial variables } & \multicolumn{2}{|c|}{ Broadband } \\
\hline & Estimate & $\operatorname{Pr}(>|t|)$ \\
\hline Intercept & 147.0 & $<0.0001$ \\
\hline BBC1 on/off & -8.7 & $<0.0001$ \\
\hline BBC2 on/off & -8.1 & $<0.0001$ \\
\hline \multirow[t]{2}{*}{ Both active } & 4.3 & $<0.0001$ \\
\hline & \multicolumn{2}{|c|}{ Smoothers } \\
\hline & edf & $\mathrm{p}$ \\
\hline$s$ (distance) & 3 & $<0.0001$ \\
\hline \multicolumn{3}{|l|}{ Model summaries } \\
\hline $\mathrm{R}^{2}$ adj. & \multicolumn{2}{|c|}{$22.9 \%$} \\
\hline Generalized cross validation & \multicolumn{2}{|c|}{85.2} \\
\hline $\mathrm{N}$ (minutes evaluated) & \multicolumn{2}{|c|}{9945} \\
\hline
\end{tabular}


end of pile driving were lower at DanTysk compared to most previous wind farm constructions. Since monopiles at DanTysk were comparable in size to those installed in other wind farms, as was the impact energy used to drive the piles, this indicates that bubble curtains were effective in reducing the number of animals disturbed and the amount of time they were disturbed. Elevated \%PPM values for the baseline in distance classes $6-12 \mathrm{~km}$ from piling could perhaps indicate that porpoises did not return to the construction site in due time for the next piling, or that other construction processes, such as guard vessel noise, led to a displacement prior to the piling.

These results play an important role in elucidating the population consequences of large-scale pile driving based on individual-based models. For harbour porpoises, the possible effects at population level are thought to arise due to accumulated energetic consequences of reduced feeding opportunities and increased energy expenditure from the deterrence itself. The energetic loss caused by a single pile driving is unlikely to translate into detectable population consequences, but since consequences add up across pile drivings, the combined impacts of multiple disturbances will at some point become significant. At present, this cumulative impact from multiple pile drivings and across multiple offshore wind farms cannot be quantified accurately, but will have to await the development of functional models, such as the DEPONS model. A large number of individual animals are simulated based on realistic assumptions about their movements, foraging and reproductive behaviour. This is modelled for many generations of virtual animals, until a stable population level is attained. At this point, disturbances, in the form of reactions to pile-driving noise, are introduced and effects on population level can be assessed. Such models are still under development, but illustrative examples are provided by New et al. (2014) for the impact of behavioural disturbance on female elephant seals and by Nabe-Nielsen et al. $(2013,2014)$ for investigating impacts of ship traffic and post-construction noise on porpoises.

If a reduction in temporary habitat loss is considered necessary for maintaining good conservation status of harbour porpoises, bubble curtains are clearly a feasible way to achieve this. Both bubble curtains used at DanTysk were capable of attenuating broadband noise levels by $8-9 \mathrm{~dB}$ on average and with an additional $4 \mathrm{~dB}$ if used together. However, this overall attenuation was not the only effect of the bubble curtains, as a pronounced change in the frequency spectrum was also evident. The bub- ble curtains at DanTysk performed particularly well above $1 \mathrm{kHz}$, a fact that was also shown for bubble curtains used at Borkum West II (Diederichs et al. 2014, Nehls et al. 2016). Noise levels above $1 \mathrm{kHz}$ at DanTysk were attenuated below ambient noise at larger distances (Figs. 4 \& 6; clearly at the 14-16 km range and likely also at the $8 \mathrm{~km}$ range). This reduction above $1 \mathrm{kHz}$ is particularly interesting with respect to impact on harbour porpoises, as thresholds for negative phonotaxis are strongly frequency dependent (Tougaard et al. 2015) and a strong correlation between reactions in captive porpoises to passing ships and frequency content above $1 \mathrm{kHz}$ has been demonstrated (Dyndo et al. 2015). If the energy above $1 \mathrm{kHz}$ is also more important than the low frequencies for pile-driving noise, it becomes important to account for the spectral content of the noise in the assessment and regulation of the impact of pile driving. At present, German regulation only considers broadband noise levels. Because most of the energy in piledriving noise is below $1 \mathrm{kHz}$, attenuation of the noise above $1 \mathrm{kHz}$, which may be the main determining factor for behavioural disturbance, is not captured to the full extent by a broadband criterion. This can be overcome by applying a frequency weighting, either the M-weighting proposed by Southall et al. (2007), or preferably an audiogram-based weighting which correlates better with experimental results (Tougaard et al. 2015). As the current German regulation only targets broadband levels and the main part of the noise energy is below $1 \mathrm{kHz}$, there will be a focus on developing mitigation methods that can reduce noise below $1 \mathrm{kHz}$. This could lead to unnecessary overregulation as it may be technically more difficult and hence more costly to reduce energy at low frequencies than at high frequencies, but if the effect on behaviour is primarily created by energy above $1 \mathrm{kHz}$, the same reduction in impact could be achieved by a targeted reduction at higher frequencies.

The worst-case scenario is a mitigation system that specifically targets low frequencies (for example by means of highly tuned Helmholz resonators; Wochner et al. 2016) and reduces these to comply with the broadband regulatory levels, but without significant reduction of noise above $1 \mathrm{kHz}$. Audiogram-weighted noise levels $L_{\text {APpho }}$ range between 24 and $33 \mathrm{~dB}$ below unweighted levels, and 18 and $28 \mathrm{~dB}$ below M-weighted levels (Table 3), illustrating that less than $10 \%$ of the energy in the pile-driving noise falls into the audible range for harbour porpoises. These matters become even more complicated when other species such as harbour seals or grey seals occur at the same site. Tuning an attenu- 
Table 3. Mean noise levels, estimated by fitting a simple transmission loss model (15 log r, no absorption) to the data in Fig. 5. Levels are referenced to $1 \mathrm{~m}$ (source level), $750 \mathrm{~m}$ (German reference distance) and $10 \mathrm{~km}$ (roughly the furthest range where effects on porpoise echolocation was observed; Table 1). SEL $L_{S S}$ single-strike sound exposure level; SEL $_{\text {cum: }}$ cumulative sound exposure level for average duration of pile driving for one foundation; $L_{5}$ and $L_{50}$ : the 50th and 5th percentiles; $\mathrm{M}_{\mathrm{hf}}$ : M-weighting for high frequency cetaceans; $A_{P p h o}$ : audiogram weighting

\begin{tabular}{|c|c|c|c|c|c|c|c|c|c|c|c|c|}
\hline \multirow[t]{2}{*}{ Weighting } & \multicolumn{3}{|c|}{ SEL $_{\mathrm{SS}}\left(\mathrm{dB}\right.$ re. $\left.\mu \mathrm{Pa}^{2} \mathrm{~s}\right)$} & \multicolumn{3}{|c|}{$\mathrm{SEL}_{\text {cum }}\left(\mathrm{dB}\right.$ re. $\left.\mu \mathrm{Pa}^{2} \mathrm{~s}\right)$} & \multicolumn{3}{|c|}{$L_{5}(\mathrm{~dB}$ re. $\mu \mathrm{Pa})$} & \multicolumn{3}{|c|}{$L_{50}(\mathrm{~dB}$ re. $\mu \mathrm{Pa})$} \\
\hline & $1 \mathrm{~m}$ & $750 \mathrm{~m}$ & $10 \mathrm{~km}$ & $1 \mathrm{~m}$ & $750 \mathrm{~m}$ & $10 \mathrm{~km}$ & $1 \mathrm{~m}$ & $750 \mathrm{~m}$ & $10 \mathrm{~km}$ & $1 \mathrm{~m}$ & $750 \mathrm{~m}$ & $10 \mathrm{~km}$ \\
\hline Broadband & 201 & 157 & 141 & 236 & 193 & 176 & 209 & 166 & 149 & 189 & 146 & 129 \\
\hline $\mathrm{M}_{\mathrm{hf}}$ & 195 & 152 & 135 & 231 & 188 & 171 & 204 & 161 & 144 & 184 & 140 & 124 \\
\hline $\mathrm{A}_{\mathrm{Ppho}}$ & 170 & 127 & 110 & 206 & 162 & 146 & 176 & 133 & 116 & 165 & 122 & 105 \\
\hline
\end{tabular}

ation system will then require taking account of all sensitive species' hearing abilities. It should be noted that bubble curtains can only effectively be deployed at shallow water depths less than $\sim 40 \mathrm{~m}$, and therefore their applicability to deeper waters may be questioned.

Reducing temporary habitat loss is not the only reason for regulating noise emissions. Both the existing German regulation (Federal Maritime and Hydrographic Agency 2014) and the upcoming regulation in Denmark (Skjellerup et al. 2015) specifically target the risk of inflicting temporary or permanent hearing damage (TTS and PTS) on porpoises during pile driving. A recent study showed that long-term exposures $(60 \mathrm{~min})$ to playbacks of pile-driving sounds induced TTS at a total cumulated sound exposure level ( $\left.\mathrm{SEL}_{\mathrm{cum}}\right)$ of approximately $180 \mathrm{~dB}$ re. $\mu \mathrm{Pa}^{2} \mathrm{~s}$ (Kastelein et al. 2015). In line with similar experiments in dolphins (Finneran et al. 2010), the effect of multiple pulses seems to be higher than the effect of a single pulse, but lower than predicted from the total cumulated SEL across all pile-driving sounds. TTS was induced in a porpoise by a single air gun pulse (which has similarities to pile-driving noise) at a sound exposure level (SELSS) of $164 \mathrm{~dB}$ re. $\mu \mathrm{Pa}^{2} \mathrm{~S}$ (Lucke et al. 2009). At DanTysk, including noise mitigation by bubble curtains, the distance at

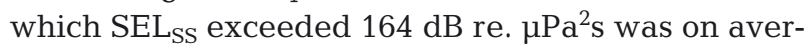
age $260 \mathrm{~m}$ from the monopiles, indicating that a porpoise would be able to acquire TTS from exposure to a single pile-driving pulse at this range and closer. As SEL cumulates across pile-driving pulses, a porpoise further away would also experience TTS if subjected to a sufficient number of pulses. Estimating the maximum distance from the monopile where a harbour porpoise could acquire TTS is not simple, as it relies critically on assumptions on how fast the animal swims away and how energy from several piledriving pulses are combined, and it is beyond the scope of this study to attempt this (see Skjellerup et al. 2015 for a thorough discussion).
A seal scarer was deployed at DanTysk prior to pile driving, in order to reduce the likelihood that porpoises (and seals) were exposed to noise levels sufficiently high to induce TTS. Seal scarers have been shown to effectively displace porpoises several kilometres (Brandt et al. 2012, 2013) and the cumulated noise exposure from pile-driving noise is therefore substantially reduced, minimizing the number of porpoises at risk of developing TTS. The results from DanTysk indicate that the seal scarer indeed deterred porpoises, up to a distance of at least $12 \mathrm{~km}$ and perhaps even $18 \mathrm{~km}$ from the pile driving, seen as a significant reduction in \%PPM (Fig. 2, Table 1). The reaction to the seal scarer was thus comparable to or even exceeded the reaction to the subsequent pile driving. This is noteworthy, as it opens up a paradoxical trade-off between the 2 impacts of the piling noise (TTS and temporary habitat loss) and the mitigation measures (seal scarer and bubble curtain). The seal scarer appears to be an efficient mitigation device to reduce the risk of inflicting TTS and PTS on porpoises, but if the deterrence effect of seal scarers is comparable to or even exceeds deterrence by pile driving itself, seal scarers merely replace one type of impact (TTS or PTS) with another (displacement). As the relative importance of these 2 impacts in terms of long-term consequences for the survival of the animals is completely unknown, it is not possible to quantify this trade-off between impacts. However, a re-evaluation of seal scarers as a mitigation measure is necessary, possibly calling for a modification of current devices especially if they are to be used in combination with effective bubble curtains. One obvious solution would be to reduce the source level of seal scarers and the duration of seal-scarer deployment, thereby also lowering their effective range. However, it is important that they remain close to $100 \%$ effective at close range. An alternative might be to increase the frequency of the seal-scarer signals, thereby exploiting the significantly higher transmission loss at higher frequencies, which would 
lead to a faster drop-off with distance from the monopile. For all of these changes, a detailed laboratory and field assessment of the effects on porpoises is necessary before large-scale utilization without dedicated monitoring. Before this study we assumed that seal scarers have at most a $7.5 \mathrm{~km}$ displacement radius, which was clearly exceeded at DanTysk, highlighting the necessity for a repetition of studies in various habitats.

In summary, we have shown that bubble curtains reduce noise emissions from pile driving significantly and in particular for frequencies above $1 \mathrm{kHz}$. Concurrent with this and most likely explained by the lower noise levels, especially above $1 \mathrm{kHz}$, the temporary habitat loss to harbour porpoises as well as the risk of TTS were reduced, both spatially and temporally. Porpoises were thus deterred from a smaller area and returned faster to the site, compared to unmitigated pile drivings of similar sized monopiles in other offshore wind farms. These findings show that bubble curtains can be effective in mitigating temporary habitat loss and risk of hearing loss for harbour porpoises in areas where concern for the conservation status of the species requires a reduction in impact. Furthermore, the results will be used to inform and further develop the DEPONS individual-based model, with the objective of quantifying the population consequences for harbour porpoises of large-scale development of offshore wind energy.

Acknowledgements. We thank Ansgar Diederichs and Caroline Höschle of BioConsult SH for coordination, logger deployments and logistics; the ships, crews and cruise leaders Christopher Honnef and Daniel Bode for assisting with data acquisition; Jeppe Dalgaard Balle for invaluable help with maintenance and programming of DSG-recorders and management of recordings; David Mann for fast response in solving unanticipated technical difficulties with DSG-recorders; and Jesper Kyed Larsen and Eva Phillipp (Vattenfall), for facilitating the project and continuous support and encouragement. Vattenfall provided the technical details about the construction process. This study is part of the DEPONS project funded by the offshore wind developers Vattenfall, Forewind, ENECO Luchterduinen, DONG Energy and ScottishPower Renewables. We thank 3 anonymous reviewers for their very helpful contributions to this publication.

\section{LITERATURE CITED}

Ainslie MA (2011) Standard for measurement and monitoring of underwater noise. Part I: physical quantities and their units. TNO, Den Haag

Bailey H, Senior B, Simmons D, Rusin J, Picken G, Thompson PM (2010) Assessing underwater noise levels during pile-driving at an offshore windfarm and its potential effects on marine mammals. Mar Pollut Bull 60:888-897
Brandt MJ, Diederichs A, Betke K, Nehls G (2011) Responses of harbour porpoises to pile driving at the Horns Rev II offshore wind farm in the Danish North Sea. Mar Ecol Prog Ser 421:205-216

* Brandt MJ, Höschle C, Diederichs A, Betke K, Matuschek R, Witte S, Nehls G (2012) Far-reaching effects of a seal scarer on harbour porpoises, Phocoena phocoena. Aquat Conserv 23:222-232

* Brandt MJ, Höschle C, Diederichs A, Betke K, Matuschek R, Nehls G (2013) Seal scarers as a tool to deter harbour porpoises from offshore construction sites. Mar Ecol Prog Ser 475:291-302

Caltrans (2009) Technical guidance for assessment and mitigation of the hydroacoustic effects of pile driving on fish. Caltrans, Sacramento, CA

Carstensen J, Henriksen OD, Teilmann J (2006) Impacts of offshore wind farm construction on harbor porpoises: acoustic monitoring of echolocation activity using porpoise detectors (T-PODs). Mar Ecol Prog Ser 321:295-308

* Dähne M, Gilles A, Lucke K, Peschko V and others (2013a) Effects of pile-driving on harbour porpoises (Phocoena phocoena) at the first offshore wind farm in Germany. Environ Res Lett 8:025002

Dähne M, Verfuss UK, Brandecker A, Siebert U, Benke H (2013b) Methodology and results of calibration of tonal click detectors for small odontocetes (C-PODs). J Acoust Soc Am 134:2514-2522

Danish Energy Authority (2006) Danish offshore wind. Key environmental issues. Danish Energy Authority, Copenhagen

Diederichs A, Pehlke H, Nehls G, Bellmann M and others (2014) Entwicklung und Erprobung des Großen Blasenschleiers zur Minderung der Hydroschallemissionen bei Offshore-Rammarbeiten. Bioconsult-SH, Husum. http:// bioconsult-sh.de/site/assets/files/1312/1312.pdf

* Dyndo M, Wiśniewska DM, Rojano-Doñate L, Madsen PT (2015) Harbour porpoises react to low levels of high frequency vessel noise. Sci Rep 5:11083

* European Commission (1992) Council Directive 92/43/EEC of 21 May 1992 on the conservation of natural habitats and of wild fauna and flora. Off J Eur Comm L 206:7-50

Federal Maritime and Hydrographic Agency (2014) Standard investigation of the impacts of offshore wind turbines on the marine environment (StUK4). BSH, Hamburg

Finneran JJ, Carder DA, Schlundt CE, Dear RL (2010) Temporary threshold shift in a bottlenose dolphin (Tursiops truncatus) exposed to intermittent tones. J Acoust Soc Am 127:3267-3272

German Federal Ministry for the Environment and Nuclear Safety (2013) Konzept für den Schutz der Schweinswale vor Schallbelastungen bei der Errichtung von OffshoreWindparks in der deutschen Nordsee (Schallschutzkonzept). BMUB, Berlin

* Gilles A, Adler S, Kaschner K, Scheidat M, Siebert U (2011) Modelling harbour porpoise seasonal density as a function of the German Bight environment: implications for management. Endang Species Res 14:157-169

*Haelters J, Dulière V, Vigin L, Degraer S (2015) Towards a numerical model to simulate the observed displacement of harbour porpoises Phocoena phocoena due to pile driving in Belgian waters. Hydrobiologia 756:105-116

Johnston DW (2002) The effect of acoustic harassment devices in harbour porpoises (Phocoena phocoena) in the Bay of Fundy, Canada. Biol Conserv 108:113-118

Kastelein RA, Hoek L, de Jong CAF, Wensveen PJ (2010) 
The effect of signal duration on the underwater detection thresholds of a harbor porpoise (Phocoena phocoena) for single frequency-modulated tonal signals between 0.25 and $160 \mathrm{kHz}$. J Acoust Soc Am 128:3211-3222

Kastelein RA, Gransier R, Marijt MAT, Hoek L (2015) Hearing frequency thresholds of harbor porpoises (Phocoena phocoena) temporarily affected by played back offshore pile driving sounds. J Acoust Soc Am 137:556-564

King SL, Schick RS, Donovan C, Booth CG and others (2015) An interim framework for assessing the population consequences of disturbance. Methods Ecol Evol 6: 1150-1158

Koschinski S, Lüdemann K (2014) Annex 1. In: Merck T, Werner S (eds) OSPAR inventory of measures to mitigate the emission and environmental impact of underwater noise. OSPAR Commission, London, p 10-40

Lucke K, Siebert U, Lepper PA, Blanchet MA (2009) Temporary shift in masked hearing thresholds in a harbor porpoise (Phocoena phocoena) after exposure to seismic airgun stimuli. J Acoust Soc Am 125:4060-4070

Lucke K, Lepper PA, Blanchet MA, Siebert U (2011) The use of an air bubble curtain to reduce the received sound levels for harbour porpoises (Phocoena phocoena). J Acoust Soc Am 130:3406-3412

* Madsen PT, Wahlberg M, Tougaard J, Lucke K, Tyack P (2006) Wind turbine underwater noise and marine mammals: implications of current knowledge and data needs. Mar Ecol Prog Ser 309:279-295

Nabe-Nielsen J, Tougaard J, Teilmann J, Lucke K, Forchhammer M (2013) How a simple adaptive foraging strategy can lead to emergent home ranges and increased food intake. OIKOS 122:1307-1316

Nabe-Nielsen J, Sibly RM, Tougaard J, Teilmann J, Sveegaard S (2014) Effects of noise and by-catch on a Danish harbour porpoise population. Ecol Model 272:242-251

Nehls G, Rose A, Diederichs A, Bellmann M, Pehlke H (2016) Noise mitigation during pile driving efficiently reduces disturbance of marine mammals. Adv Exp Med Biol 875:755-762

New LF, Clark JS, Costa DP, Fleishman E and others (2014) Using short-term measures of behaviour to estimate long-term fitness of southern elephant seals. Mar Ecol Prog Ser 496:99-108

NMFS (National Marine Fisheries Service) (2016) Technical guidance for assessing the effects of anthropogenic sound on marine mammal hearing underwater acoustic thresholds for onset of permanent and temporary threshold shifts. NOAA Technical Memorandum NMFS-OPR55. NMFS, Silver Spring, MD

R Core Development Team (2014) R: A language and environment for statistical computing. R Foundation for Statistical Computing, Vienna

Reinhall PG, Dahl PH (2011) Underwater Mach wave radia- tion from impact pile driving: theory and observation. J Acoust Soc Am 130:1209-1216

Rustemeier J, Grießmann T, Rolfes R (2012) Underwater sound mitigation of bubble curtains with different bubble size distributions. Proc Mtgs Acoust 17:070055

Scheidat M, Tougaard J, Brasseur S, Carstensen J, Petel Tv P, Teilmann J, Reijnders P (2011) Harbour porpoises (Phocoena phocoena) and wind farms: a case study in the Dutch North Sea. Environ Res Lett 6:025102

* Shapiro AD, Tougaard J, Jorgensen PB, Kyhn LA and others (2009) Transmission loss patterns from acoustic harassment and deterrent devices do not always follow geometrical spreading predictions. Mar Mamm Sci 25:53-67

Skjellerup P, Maxon CM, Tarpgaard E, Thomsen F, Schack HB, Tougaard J, Teilmann J, Madsen KN, Mikaelsen MA, Heilskov NF (2015) Marine mammals and underwater noise in relation to pile driving - report of working group. Energinet.dk

Southall BL, Bowles AE, Ellison WT, Finneran J and others (2007) Marine mammal noise exposure criteria. Aquat Mamm 33:411-521

* Terhune JM (2013) A practical weighting function for harbour porpoise underwater sound level measurements. J Acoust Soc Am 134:2405-2408

* Tougaard J, Carstensen J, Teilmann J, Skov H, Rasmussen P (2009) Pile driving zone of responsiveness extends beyond $20 \mathrm{~km}$ for harbour porpoises (Phocoena phocoena (L.)). J Acoust Soc Am 126:11-14

Tougaard J, Wright AJ, Madsen PT (2015) Cetacean noise criteria revisited in the light of proposed exposure limits for harbour porpoises. Mar Pollut Bull 90:196-208

van Beest FM, Nabe-Nielsen J, Carstensen J, Teilmann J, Tougaard J (2015) Disturbance effects on the harbour porpoise population in the North Sea (DEPONS): status report on model development. Scientific Report from DCE - Danish Centre for Environment and Energy No. 140. DCE, Aarhus

*Wensveen PJ, Huijser LAE, Hoek L, Kastelein RA (2014) Equal latency contours and auditory weighting functions for the harbour porpoise (Phocoena phocoena). J Exp Biol 217:359-369

WWochner M, Lee K, McNeese A, Wilson P (2016) Underwater noise mitigation from pile driving using a tuneable resonator system. In: Miyara F, Accolti E, Pasch V, Vechiatti $\mathrm{N}$ (eds) Proceedings of the 22nd International Congress on Acoustics, Buenos Aires. Wind Farm Noise: Paper ICA2016-0503

*Wood SN (2011) Fast stable restricted maximum likelihood and marginal likelihood estimation of semiparametric generalized linear models. J R Stat Soc B 73:3-36

Würsig B, Greene CR, Jefferson TA (2000) Development of an air bubble curtain to reduce underwater noise of percussive piling. Mar Environ Res 49:79-93 


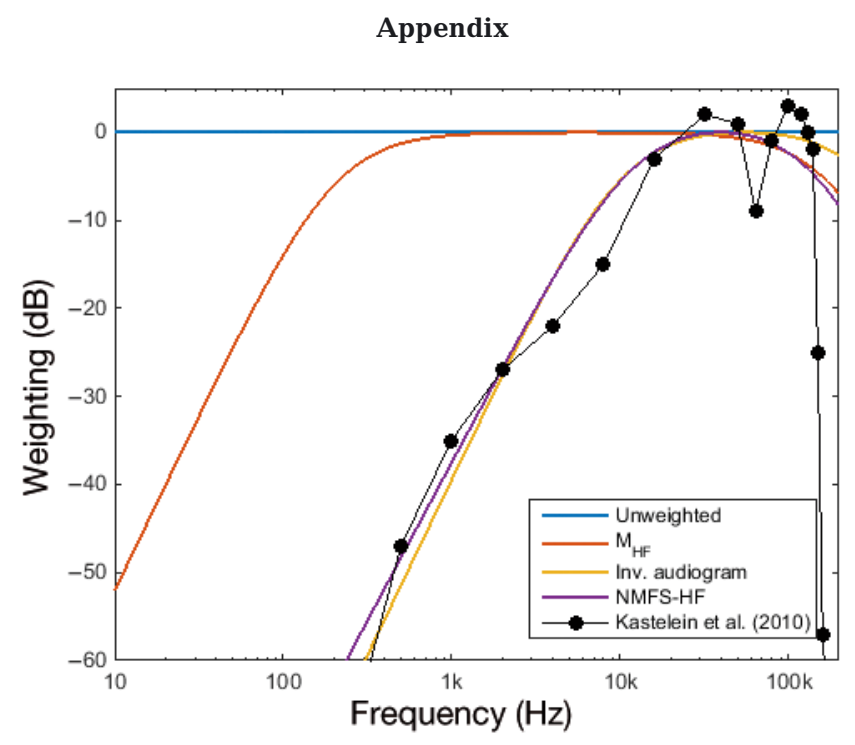

Fig. A1. Weighting functions: unweighted, $\mathrm{M}_{\mathrm{HF}}$ (Southall et al. 2007), inverted porpoise audiogram (present study) and inverted HF-cetacean audiogram (NMFS 2016). The porpoise audiogram from Kastelein et al. (2010) has been added for comparison

Editorial responsibility: Elliott Hazen,

Pacific Grove, California, USA
Submitted: July 29, 2016; Accepted: July 12, 2017

Proofs received from author(s): September 24, 2017 